\title{
Health-related quality of life and its predictors among patients with breast cancer at Tikur Anbessa Specialized Hospital, Addis Ababa, Ethiopia
}

Selamawit Gebrehiwot Sibhat ${ }^{1}$, Teferi Gedif Fenta ${ }^{1}$, Beate Sander ${ }^{2,3,4}$ and Gebremedhin Beedemariam Gebretekle ${ }^{1 *}$ (D)

\begin{abstract}
Background: Breast cancer is the second most prevalent malignancy in Ethiopia and severely affects patients' health-related quality of life (HRQOL). We aimed to assess HRQoL, factors influencing HRQoL, and utilities among breast cancer patients at Tikur Anbessa Specialized Hospital, Addis Ababa, Ethiopia.

Methods: A hospital-based cross-sectional study was conducted in Tikur Anbessa Specialized Hospital from December 2017 to February, 2018. A total of 404 breast cancer patients were interviewed using the validated Amharic version of the European Organization for Research and Treatment of Cancer module (EORTC QLQ-C30), EORTC QLQ-BR23, and Euro Quality of Life Group's 5-Domain Questionnaires 5 Levels (EQ-5D-5 L) instruments. Mean scores and mean differences of EORTC- QLQ-C30 and EORTC- QLQ-BR23 were calculated. One-way ANOVA test was employed to determine the significance of mean differences among dependent and independent variables while stepwise multivariate logistic regression was used to identify factors associated with the global quality of life (GQOL). Coefficients and level specific utility values obtained from a hybrid regression model for the Ethiopian population were used to compute utility values of each health state. Data was analyzed using SPSS version 23.

Results: The mean age of patients was $43.94 \pm 11.72$ years. The mean score for GQoL and visual analog scale was $59.32 \pm 22.94$ and $69.94 \pm 20.36$, respectively while the mean utility score was $0.8 \pm 0.25$. Predictors of GQoL were stage of cancer ( $A O R=7.94 ; 95 \% \mathrm{Cl}: 1.83-34.54)$, cognitive functioning ( $\mathrm{AOR}=2.38 ; 95 \% \mathrm{Cl}$ : 1.32-4.31), pain ( $\mathrm{AOR}=$ 7.99; $95 \% \mathrm{Cl}: 4.62-13.83)$, financial difficulties ( $\mathrm{AOR}=2.60 ; 95 \% \mathrm{Cl}: 1.56-4.35)$, and future perspective ( $\mathrm{AOR}=2.08$; 95\% Cl: 1.24-3.49).

Conclusions: The overall GQoL of breast cancer patients was moderate. Targeted approaches to improve patients' HRQoL should consider stage of cancer, cognitive functioning, pain, financial status and worries about the patient's future health. This study also provides estimates of EQ-5D utility scores that can be used in economic evaluations.
\end{abstract}

Keywords: Breast cancer, Health-related quality of life, HRQoL, EORTC-QLQ-C30, EORTC-QLQ-BR23, EQ5D, Utility

\footnotetext{
* Correspondence: gebremedhin.beedemariam@aau.edu.et

${ }^{1}$ School of Pharmacy, College of Health Sciences, Addis Ababa University,

Zambia Street, Addis Ababa, Ethiopia

Full list of author information is available at the end of the article
}

(c) The Author(s). 2019 Open Access This article is distributed under the terms of the Creative Commons Attribution 4.0 International License (http://creativecommons.org/licenses/by/4.0/), which permits unrestricted use, distribution, and reproduction in any medium, provided you give appropriate credit to the original author(s) and the source, provide a link to the Creative Commons license, and indicate if changes were made. The Creative Commons Public Domain Dedication waiver (http://creativecommons.org/publicdomain/zero/1.0/) applies to the data made available in this article, unless otherwise stated. 


\section{Introduction}

Breast cancer is a growing concern worldwide as the leading cause of mortality and morbidity among women in developed and developing countries [1]. It has been predicted that the worldwide incidence of breast cancer will reach approximately 3.2 million new cases per year by 2050 [2]. Approximately $60 \%$ of deaths due to breast cancer occur in developing countries [3]. Cancer incidence in Ethiopia has been increasing over time and breast cancer is the most prevalent malignancy (30.2\%) followed by cancer of the cervix (13.4\%) and colorectal cancer (5.7\%) among adults [4]. Consequently, cancer is emerging as a critical public health problem in Ethiopia [5, 6].

The impact of cancer, however, is far greater than the number of cases would suggest. Patients with breast cancer experience physical symptoms and psychosocial distress that adversely affect their health-related quality of life (HRQoL). The World Health Organization defined HRQoL as involving a person's physical health, psychological state, degree of independence, social relationships, personal beliefs and environment [7]. HRQoL measures wellbeing related to or affected by the presence of a disease or treatments and it generally consists of a number of domains including physical functioning, psychological well-being (such as levels of anxiety and depression), and social support [8]. Ongoing symptoms, side effects of treatments, recurrence often result in a feeling of distress that affects physical and psychological functioning and impacts on lifestyle and social engagements of patients with breast cancer [9]. Patients receiving chemotherapy might also experience several side-effects and symptoms that negatively affect their HRQoL [10].

Deterioration of patients' HRQoL is more pronounced in developing counties since breast cancer is diagnosed at advanced stages and as a result, treatment cannot be efficiently executed [3]. As breast cancer is the leading cause of morbidity and mortality among women with cancer in Ethiopia, HRQoL among patients with breast cancer is given minimal attention. Thus, assessing HRQoL, associated factors and utility would be helpful to inform interventions and improves patient outcome [11].

\section{Methods}

\section{Study setting}

The study was conducted at Tikur Anbessa Specialized Hospital (TASH), the largest teaching hospital under the administration of Addis Ababa University in Ethiopia. The hospital was established in 1972 and has more than 800 beds providing diagnostic and treatment service for about 370,000 to 400,000 patients per year. The oncology unit at TASH is the largest referral site for the country, providing service for over 60,000 patients annually.
It is the sole oncology referral and radiotherapy center in the entire country [12].

\section{Study variables \\ Dependent variables: GQoL, functional scales, symptom scales \\ Independent variables:}

- Socio-demographic characteristics such as age, marital status, level of education, and average monthly household income (AMHI).

- Clinical characteristics such as patient status, time since diagnosis, stage of cancer, current type of anticancer treatment and comorbid conditions.

- Functional scales

- Symptom scales

\section{Study design and participants}

We conducted a hospital-based cross-sectional study in patients with breast cancer at the outpatient oncology unit of TASH between December 2017 and February 2018. The sample size was calculated using the single proportion formula [13]. Due to absence of studies done using Euro Quality of Life Group's 5-Domain Questionnaires 5 Levels (EQ-5D-5 L) and with the intention of obtaining maximum sample size, an estimate proportion of patients that have utility values above the average was considered to be $50 \%$, was used to calculate the sample size.

$$
n=\frac{\left(\mathrm{z} \frac{\alpha}{2}\right)^{2} \mathrm{p}(1-\mathrm{p})}{\mathrm{d}^{2}}
$$

Where: $\mathbf{n}=$ required sample size.

$\mathbf{Z}_{\mathbf{\alpha} / \mathbf{2}}=1.96(\mathrm{Z}=$ score corresponds to $95 \%$ confidence level).

$\mathbf{P}=$ proportion of patients with utility above the average.

$$
\begin{aligned}
& \mathbf{d}^{2}=\text { margin of error }(0.05) \\
& n=\frac{(1.96)^{2}(0.5)(0.5)}{(0.05) 2}=384
\end{aligned}
$$

Considering a 5\% of contingency for inappropriate and nonresponses, finally we interviewed a total of 404 patients. Since we used a face-to-face interview, all eligible patients approached were willing to participate in the study and none of the patient data were incomplete. Participants were recruited consecutively until the required sample size was reached.

Female patients pathologically diagnosed with breast cancer; both new and follow up were eligible for the study. Patients who were pregnant, critically ill (too weak to communicate, as per the assessment of oncologist), have a psychiatric disorder, can't speak and/or read 
Amharic language, or are unwilling to participate in the study were excluded.

Data was collected by two trained oncology nurses working within the oncology clinic. Two days training was given for the oncology nurses focusing on; the contents of the questionnaire, the identification of patients based on the inclusion/exclusion criteria, and how to get consent. Participants were assured of anonymity and confidentiality of their information obtained in the study by excluding any personal identifier in the data collection form. They were also reassured that the report of the findings would not identify them and only the aggregate data would be reported. All the collected data were checked for completeness by the principal investigator on a daily basis.

\section{Instruments and scoring}

We used the validated Amharic version (official language of Ethiopia and the study area) of three data collection instruments: EORTC QLQ-C30, EORTC QLQ-BR23 and EQ-5D-5 L (Additional file 1).

i. EORTC QLQ-C30: The EORTC QLQ-C30 consists of five functional scales (physical, emotional, role, cognitive, and social functioning), nine symptom scales (fatigue, nausea/vomiting, pain, dyspnea, insomnia, appetite loss, constipation, diarrhea and financial difficulties) and the GQoL scale, which aims to provide a multidimensional assessment of the HRQoL of patients based on 28 questions using a four-point scale. Two additional questions were used to determine the state of health on a sevenpoint Likert scale. Each of the multi-item scales includes a different set of items, no item occurs in more than one scale [14].

ii. EORTC QLQ-BR23: The side-effects of therapy and tumour-related symptoms in patients with breast cancer was determined and recorded using the additional EORTC QLQ-BR23 module, which consists of 23 questions distributed across eight (sexual functioning, future perspective, body image, sexual enjoyment, systemic therapy, breast symptoms, arm symptoms, and upset by hair loss) with a four-point scales; from $1=$ not at all to $4=$ very much [14].

iii. $E Q-5 D-5 L$ :The generic EQ-5D-5 L questionnaire assessed the HRQoL across five dimensions (mobility, self-care, usual activities, pain/discomfort, and anxiety/depression), with a 5-level response (from $1=$ no problem to $5=$ extreme problem) and the EQ-VAS scale on which the overall state of health is marked by the patient in the form of a number $(0=$ worst imaginable state of health, $100=$ best imaginable state of health). The utility value between the worst and best health state is on a scale from 0 to 1 , where 0 denotes death and 1 denotes perfect health. EQ-5D-5 L is highly discriminatory, easy to use and can generate a single total score based on socially relevant measures of HRQoL [15].

Both EORTC QLQ-C30 and EORTC QLQ-BR23 are composed of both multi-item scales and single-item measures. Each of the multi-item scales includes a different set of items, no item occurs in more than one scale. The principle for scoring the EORTC QLQ-C30 and EORTC QLQ-BR23 scales is the same in all cases which starts with estimating the average of the items that contribute to the scale (raw score) and using a linear transformation to standardize the raw score. Scores range from 0 to 100; a higher score represents a higher ("better") level of functioning, or a higher ("worse") level of symptoms [14]. The two items for the scales are scored positively (i.e. "very much" is best) and therefore use the same algebraic equation as for symptom scales which is reversely coded; however, the Body Image scale uses the algebraic equation for functioning scales [16].

\section{Data analysis and interpretation}

Statistical analysis was undertaken using SPSS 23.0. Analyzing the data, responses were reverse coded as appropriate. Simple descriptive statistics such as frequencies, means, and standard deviations (SD) were employed to report the socio-demographic characteristics, clinical characteristics, EORTC QLQ-C30, EORTC QLQ-BR23, EQ-5D-5 L, and EQ VAS scores. Multivariable logistic regression was carried out to identify possible predicting factors for GQoL. GQoL, symptom and functional scales have been dichotomized into "Affected at any degree" and "Not affected at all". A score below 75 (above 75 mean no problem at all) for functional and GQoL scales were defined as "Affected at any degree". Scores above a 25 mean (below 25 indicates no symptom at all) were defined as "Affected at any degree" and binary logistic regression was conducted between the GQoL and independent variables to obtain candidate variables for multi-variable logistic regression analysis. Variables with $p$-value $<0.25$ were candidate for multiple regression analysis. Due to many independent variables, forward stepwise method was used for the multivariable analysis and significance of association was determined at $p$ value $<0.05$. Patient's utility score is obtained using possible (3125) health states of patients with breast cancer defined by the 5 dimensions and disutility coefficient of general population. Thus, it was calculated using the Ethiopian general population utility value set [17]. One caveat in order is the limitation within the analysis where causality of the associations was not confirmed. 


\section{Results}

Socio-demographic and clinical characteristics of patients All 404 patients completed the questionnaires, i.e., there were no missing responses. Patients' mean age was $43.94 \pm 11.72$ years and more than two-thirds of patients (70.2\%) attended formal education. The average monthly household income (AMHI) was $2634 \pm 3373$ Ethiopian Birr $(\$ 1=27.4 \mathrm{ETB})$ and one-third of patients (31.9\%) had an AMHI of $\leq 600$ ETB. The majority (89.4\%) of patients were on follow-up and more than half (52.7\%) were diagnosed within the past year. Regarding the severity of disease, $142(35.1 \%)$ and 134 (33.2\%) of patients with breast cancer were in cancer stage III and II, respectively. Most patients (52.5\%) received surgical treatment and 318 (78.7\%) had no comorbid conditions (Table 1).

\section{Global quality of life}

The GQoL mean score was $59.32 \pm 22.94$. Functional scale mean scores ranged from $67.97 \pm 25.15$ for physical functioning to $80.07 \pm 30.08$ for social functioning. All the symptom scales and items except for nausea/vomiting, dyspnea, constipation, and diarrhea scored above 25 . With regard to EORTC QLQ-BR23 functioning scales/ items, body image was the highest score (77.21 \pm 32.09$)$, while sexual functioning recorded the lowest score $(17.78 \pm 28.09)$. Except for breast symptoms and arm symptoms, all others scored above 25 for the symptom scales and items (Table 2).

\section{Mean differences of EORTC QLQ-C30 and EORTC QLQ-BR23} scales with socio-demographic and clinical characteristics

Family income showed a significant mean difference with GQoL, physical functioning and role functioning on the functional scales. Similarly, family income showed significant mean differences with constipation and financial difficulties on the symptom scales. The other sociodemographic variables, however, showed no significant mean difference with EORTC QLQ-C30. Moreover, patients with stage 4 cancer scored the lowest mean in GQoL, physical function and role functioning. Type of treatment showed a significant mean difference and those who were treated with radiotherapy scored the lowest mean in their GQoL, role functioning, emotional functioning and cognitive functioning. Stage 4 cancer patients had a higher mean score on fatigue, nausea and vomiting, pain, dyspnea, insomnia and appetite loss except for diarrhea and financial difficulties. Patients who took chemotherapy had a higher score in nausea and vomiting, appetite loss and diarrhea while those who took radiotherapy had a higher score on pain. However, the other symptom scales were not significant with treatment and comorbid conditions (Additional file 2). Further details are presented in Additional file 2.
Table 1 Socio-demographic and clinical characteristics of patients with Breast cancer at TASH, Addis Ababa, Ethiopia

\begin{tabular}{|c|c|}
\hline Study Variables & n (\%) \\
\hline \multicolumn{2}{|l|}{ Age (years) } \\
\hline $15-24$ & $3(0.7)$ \\
\hline $25-54$ & $320(79.2)$ \\
\hline $55-64$ & $57(14.1)$ \\
\hline$>65$ & $24(5.9)$ \\
\hline \multicolumn{2}{|l|}{ Marital status } \\
\hline Single & $56(13.9)$ \\
\hline Married & $232(57.4)$ \\
\hline Divorced & $56(13.9)$ \\
\hline Widowed & $60(14.9)$ \\
\hline \multicolumn{2}{|l|}{ Level of education } \\
\hline Illiterate (neither read nor write) & $92(22.8)$ \\
\hline Informal education & $28(6.9)$ \\
\hline Primary education & $76(18.8)$ \\
\hline Secondary education & $123(30.4)$ \\
\hline Higher education (certificate, diploma, and above) & $85(21.0)$ \\
\hline \multicolumn{2}{|l|}{ AMHI, in ETB } \\
\hline$\leq 600$ & $129(31.9)$ \\
\hline$>600$ & $275(68.1)$ \\
\hline \multicolumn{2}{|l|}{ Patient status } \\
\hline New patient & $43(10.6)$ \\
\hline Follow up & $361(89.4)$ \\
\hline \multicolumn{2}{|l|}{ Time since diagnosis (months) } \\
\hline$<12$ months & $213(52.7)$ \\
\hline 13-60 months & $154(38.1)$ \\
\hline$>61$ months & $37(9.2)$ \\
\hline \multicolumn{2}{|l|}{ Stage of cancer } \\
\hline Stage I & $13(3.2)$ \\
\hline Stage II & $134(33.2)$ \\
\hline Stage III & $142(35.1)$ \\
\hline Stage IV & $84(20.8)$ \\
\hline Undefined & $31(7.7)$ \\
\hline \multicolumn{2}{|l|}{ Current treatment } \\
\hline Surgery & $212(52.5)$ \\
\hline Chemotherapy & $24(5.9)$ \\
\hline Hormonal therapy & $139(34.4)$ \\
\hline Radiotherapy & $29(7.2)$ \\
\hline \multicolumn{2}{|l|}{ Comorbid conditions } \\
\hline Yes & $86(21.3)$ \\
\hline No & 318 (78.7) \\
\hline
\end{tabular}


Table 2 Mean score value of the EORTC QLQ-C30 and EORTC QLQ-BR23 Scales Variables of patients with Breast cancer at TASH, Addis Ababa, Ethiopia

\begin{tabular}{|c|c|c|}
\hline & $\begin{array}{l}\text { EORTC QLQ-C30 and EORTC } \\
\text { QLQ-BR23 Scales }\end{array}$ & Mean \pm SD \\
\hline \multirow[t]{17}{*}{ EORTC QLQ- C30 } & GQoL & $59.32 \pm 22.94$ \\
\hline & \multicolumn{2}{|l|}{ Functional scales } \\
\hline & Physical functioning & $67.97 \pm 25.15$ \\
\hline & Role functioning & $73.18 \pm 36.19$ \\
\hline & Emotional functioning & $71.51 \pm 29.74$ \\
\hline & Cognitive functioning & $78.55 \pm 26.23$ \\
\hline & Social functioning & $80.07 \pm 30.08$ \\
\hline & \multicolumn{2}{|l|}{ Symptom scales and Items } \\
\hline & Fatigue & $42.38 \pm 33.35$ \\
\hline & Nausea and Vomiting & $14.48 \pm 24.96$ \\
\hline & Pain & $36.46 \pm 32.91$ \\
\hline & Dyspnoea & $18.65 \pm 30.69$ \\
\hline & Insomnia & $33.16 \pm 39.85$ \\
\hline & Appetite loss & $36.47 \pm 40.69$ \\
\hline & Constipation & $24.83 \pm 35.72$ \\
\hline & Diarrhea & $4.04 \pm 14.76$ \\
\hline & Financial Difficulties & $48.59 \pm 44.56$ \\
\hline \multirow[t]{10}{*}{ EORTC QLQ-BR23 } & \multicolumn{2}{|l|}{ Functional scales } \\
\hline & Body image & $77.21 \pm 32.09$ \\
\hline & Sexual functioning & $17.78 \pm 28.09$ \\
\hline & Sexual enjoyment & $63.51 \pm 30.98$ \\
\hline & Future perspective & $52.47 \pm 43.13$ \\
\hline & \multicolumn{2}{|l|}{ Symptom scales/items } \\
\hline & Systemic therapy side effects & $34.11 \pm 22.59$ \\
\hline & Breast symptoms & $18.39 \pm 22.71$ \\
\hline & Arm symptoms & $24.92 \pm 25.06$ \\
\hline & Upset by hair loss & $26.92 \pm 40.24$ \\
\hline
\end{tabular}

\section{Factors of quality of life}

In multivariable analysis, five variables (stage of cancer, cognitive functioning, pain, financial difficulties, and future perspective) were found to be significantly associated with patients' GQOL (Tables 3 and 4). Only cancer stage maintained a significant association with the sociodemographic and clinical characteristics. This implied that stage 4 breast cancer patients were 7.94 times more likely that their GQoL was affected by cancer (Table 3).

For EORTC QLQ-C30, only cognitive functioning was significant. Thus, patients GQoL was 2.38 times more likely to be affected if they reported problems with cognitive functioning. Among the symptom scale variables, pain and financial difficulties maintained their association in the multivariable analysis. Patients GQoL was 8 times more likely to be affected if they reported problems with pain. Patients GQoL was 2.60 times more likely to be affected if they reported problems with financial difficulties. For the breast specific EORTC QLQBR23 of the functional scales, only future perspective maintained the association in the multi-variable analysis $(\mathrm{AOR}=2.08 ; 95 \%$ CI: $1.24-3.49)$ (Table 4).

\section{EQ-5D dimensions affected by breast Cancer and utility score}

For the EQ-5D-5 L, except for pain variable, more than half of the patients had no problem in any of the five dimensions. The study showed that $23.8,4.2$, and $1 \%$ of the patients reported slight to moderate, severe mobility problem, and unable to walk, respectively. According to the study, $9.9 \%$ of them reported a slight to moderate self-care problem while $1.7 \%$ of them were unable to wash or dress themselves. Regarding daily activities, $27.4 \%$ of the patients reported that they experienced slight to moderate problems in their daily activity with $3.5 \%$ were unable to do their usual activities. $43.3 \%$ of the patients reported that they suffered slight to moderate pain, $6.9 \%$ suffered a severe pain and $4.5 \%$ suffered an extreme pain. Considering depression/anxiety, 30.2, 7.4, and $2.7 \%$ of the patients suffered a slight to moderate, severe, and an extreme anxiety/depression, respectively (Fig. 1).The mean score for the EQ-VAS was $69.94 \pm 20.36$, while the mean utility score was found to be $0.8 \pm 0.25$., which translates to patients with breast cancer preferred to trade-off 2 years of live and preferred to live 8 years in full health compared to living 10 years with their current health status.

\section{Discussion}

The purpose of the study was to assess HRQoL, predicting factors and utility among patients with breast cancer in TASH. In the assessment of functioning scales, the lowest score was found for physical and sexual functioning. Highest symptom scales were found for fatigue, pain, loss of appetite and systemic therapy side effects were reported. The mean score for GQoL was $59.32 \pm$ 22.94 which is almost similar to studies conducted in Iran, Central rural India, Germany and Lebanon [10, 18-20]. Our finding, however, was lower than the EORTC reference value $(61.8 \pm 24.6)$ [21] and studies conducted in South India, Australia, UK, Bahrain, Jordan, and Latin America [21-26]. This could be due to limited understanding of the disease, the lengthy process of referral to the country's only specialized center, and late presentation; with most patients at the center diagnosed in a metastasized level which makes the disease incurable [27].

Physical and cognitive functioning were lower than the reference value, whereas role, emotional and social functioning were higher than the reference value [28]. 
Table 3 Association of socio-demographic/economic factors with GQoL of patients with breast cancer at TASH, Addis Ababa, Ethiopia

\begin{tabular}{|c|c|c|c|c|c|}
\hline & \multirow[t]{2}{*}{ Variables } & \multicolumn{2}{|l|}{ GQoL } & \multirow[t]{2}{*}{ COR $(95 \% \mathrm{Cl})$} & \multirow[t]{2}{*}{ AOR $(95 \% \mathrm{Cl})$} \\
\hline & & Affected & Not affected & & \\
\hline \multirow[t]{9}{*}{ Socio-demographic/economic } & Educational status & & & & \\
\hline & Illiterate & $69(25.1)$ & $23(17.8)$ & 1.00 & \\
\hline & Informal & $21(7.6)$ & $7(5.5)$ & $1.00(0.38-2.66)$ & \\
\hline & Primary & $56(20.4)$ & $20(15.5)$ & $0.93(0.47-1.87)$ & \\
\hline & Secondary & $84(30.5)$ & $39(30.2)$ & $0.72(0.39-1.32)$ & \\
\hline & Higher & $45(16.4)$ & $40(31.0)$ & $0.38(0.19-0.71)$ & \\
\hline & $\mathrm{AMHI}$ & & & & \\
\hline & $\leq 600$ & $100(36.4)$ & $29(22.5)$ & 1.00 & \\
\hline & $>600$ & $175(63.6)$ & $100(77.5)$ & $0.51(0.31-0.82)$ & \\
\hline \multirow[t]{11}{*}{ Clinical characteristics } & Stage of cancer & & & & \\
\hline & Stage 1 & $7(2.6)$ & $6(4.7)$ & 1.00 & \\
\hline & Stage 2 & $86(31.3)$ & $48(37.3)$ & $1.54(0.49-4.83)$ & $3.09(0.79-12.09)$ \\
\hline & Stage 3 & $93(33.8)$ & $49(38.0)$ & $1.63(0.52-5.11)$ & $3.08(0.79-12.01)$ \\
\hline & Stage 4 & $71(25.8)$ & $13(10.0)$ & $4.68(1.35-16.18)$ & $7.94(1.83-34.54) *$ \\
\hline & Undefined & $18(6.5)$ & $13(10.0)$ & $1.19(0.32-4.37)$ & $2.04(0.43-9.61)$ \\
\hline & Current Treatment & & & & \\
\hline & Chemo therapy & $151(54.9)$ & $61(47.3)$ & 1.00 & \\
\hline & Surgery & $15(5.5)$ & $9(6.9)$ & $0.67(0.28-1.62)$ & \\
\hline & Hormonal therapy & $85(30.9)$ & $54(41.9)$ & $0.64(0.40-0.99)$ & \\
\hline & Radiotherapy & $24(8.7)$ & $5(3.9)$ & $1.94(0.71-5.32)$ & \\
\hline
\end{tabular}

Symptom scales of the EORTC-C30 were higher than the reference value except for diarrhea, which implied that the patient with breast cancer were very symptomatic. Fatigue and financial difficulties were the highest complaints. The mean score of financial difficulties of this study were higher than studies conducted in Nepal, Iran, Kuwait and Nigeria [10, 29-31]. The current study also showed that household income had a significant mean difference with GQoL, and $31.9 \%$ of the study participants were below the poverty line [32]. And since TASH is a destination for patients from every corner of the country, transport and hospitality fees in Addis Ababa are not easily affordable, and this could have contributed to the higher scores of financial difficulties [6].

Regarding the breast specific assessment tool, the mean results of the functional and symptom subscales in this study were higher than results of the studies conducted in Kuwait and Morocco [30,33] but lower than studies conducted in south India, Germany, UK, Bahrain, Iran, and Latin [10, 19, 22, 24-26]. The burden of breast cancer in Ethiopian women may be higher because of limited healthcare access with only a single radiotherapy center in the country [6]. This might exacerbate symptoms because of long waiting times. This might be also attributed to a limited psychological support for breast cancer patients in the Ethiopian health care system and community.

Pain was the major predictor factor of GQoL; the significant mean difference showed that stage 4 breast cancer patients and patients who were on chemotherapy and radiotherapy had higher mean result. The current results from the EQ-5D-5 L also support that pain is a major complaint among breast cancer patients in TASH. A study conducted in Ethiopia also reported the inadequacy of cancer pain management [34]. Another study also suggested that early symptom screening should be incorporated into nursing assessment procedures for a better outcome [35].

Cancer Stage 4 was found to be one of the GQoL predictors. A significant mean difference was also seen between GQoL and stage 4 patients. The association between cancer stage and GQoL were similar to a study conducted in Bahrain [25]. Considering the access of cancer treatment in Ethiopia, Which is accompanied by long waiting time, it is difficult for a great majority of the population to access cancer treatment services. In Addition to that, the low awareness of cancer signs and symptoms, inadequate screening and early detection and treatment services, inadequate diagnostic facilities and country's very few cancer specialists, also results in many 
Table 4 Association between (EORTC QLQ-C30, EORTC QLQ-BR23) functioning and symptom scales with GQoL of patients with breast cancer at TASH, Addis Ababa, Ethiopia

\begin{tabular}{|c|c|c|c|c|c|c|}
\hline & \multirow[t]{2}{*}{ Variable } & & \multicolumn{2}{|l|}{ GQOL } & \multirow[t]{2}{*}{ COR $(95 \% \mathrm{Cl})$} & \multirow[t]{2}{*}{ AOR $(95 \% \mathrm{Cl})$} \\
\hline & & & Affected & Not affected & & \\
\hline \multirow[t]{30}{*}{ EORTC QLQ C-30 } & Functional scales & & & & & \\
\hline & Physical functioning & Affected & $187(68.0)$ & $46(35.7)$ & $3.83(2.47-5.96)$ & \\
\hline & & Not affected & $88(32.0)$ & $83(64.3)$ & 1.00 & \\
\hline & Role Functioning & Affected & $139(50.5)$ & $18(14.0)$ & $6.30(3.63-10.94)$ & \\
\hline & & Not affected & $136(49.5)$ & $111(86.0)$ & 1.00 & \\
\hline & Emotional Functioning & Affected & $134(48.7)$ & $30(23.3)$ & $3.14(1.96-5.03)$ & \\
\hline & & Not affected & $141(51.3)$ & $99(76.7)$ & 1.00 & \\
\hline & Cognitive Functioning & Affected & $121(44.0)$ & $23(17.8)$ & $3.62(2.18-6.03)$ & $2.38(1.32-4.31)^{*}$ \\
\hline & & Not affected & $154(56.0)$ & $106(82.2)$ & 1.00 & 1.00 \\
\hline & Social Functioning & Affected & $104(37.8)$ & $27(20.9)$ & $2.29(1.41-3.75)$ & \\
\hline & & Not affected & $171(62.2)$ & $102(79.1)$ & 1.00 & \\
\hline & Symptom scales & & & & & \\
\hline & Fatigue & Affected & $204(74.2)$ & $45(34.9)$ & $5.36(3.41-8.43)$ & \\
\hline & & Not affected & $71(25.8)$ & $84(65.1)$ & 1.00 & \\
\hline & Nausea and Vomiting & Affected & 87 (31.6) & $14(10.9)$ & $3.80(2.07-6.99)$ & \\
\hline & & Not affected & $188(68.4)$ & $115(89.1)$ & 1.00 & \\
\hline & Pain & Affected & $195(70.9)$ & $26(20.2)$ & $9.66(5.84-15.96)$ & $7.99(4.62-13.83)^{*}$ \\
\hline & & Not affected & $80(29.1)$ & $103(79.8)$ & 1.00 & 1.00 \\
\hline & Dyspnoea & Affected & $113(41.1)$ & $18(14.0)$ & $4.30(2.47-7.48)$ & \\
\hline & & Not affected & $162(58.9)$ & $111(86.0)$ & 1.00 & \\
\hline & Insomnia & Affected & $152(55.3)$ & $37(28.7)$ & $3.07(1.96-4.82)$ & \\
\hline & & Not affected & $123(44.7)$ & $92(71.3)$ & 1.00 & \\
\hline & Appetite loss & Affected & $166(60.4)$ & $38(29.5)$ & $3.65(2.33-5.72)$ & \\
\hline & & Not affected & 109 (39.6) & $91(70.5)$ & 1.00 & \\
\hline & Constipation & Affected & $122(44.4)$ & $35(27.1)$ & $2.14(1.36-3.38)$ & \\
\hline & & Not affected & $153(55.6)$ & $94(72.9)$ & 1.00 & \\
\hline & Diarrhea & Affected & $27(9.8)$ & $7(5.4)$ & $1.89(0.80-4.48)$ & \\
\hline & & Not affected & $248(90.2)$ & $122(94.6)$ & 1.00 & \\
\hline & Financial Difficulties & Affected & $187(68.0)$ & $54(41.9)$ & $2.95(1.92-4.55)$ & $2.60(1.56-4.35)^{*}$ \\
\hline & & Not affected & $88(32.0)$ & $75(58.1)$ & 1.00 & 1.00 \\
\hline \multirow[t]{12}{*}{ EORTC QLQ BR-23 } & Functional scales & & & & & \\
\hline & Sexual functioning & Affected & $70(25.5)$ & $50(38.8)$ & $0.54(0.35-0.84)$ & \\
\hline & & Not affected & $205(74.5)$ & $79(61.2)$ & 1.00 & \\
\hline & Future Perspective & Affected & $181(65.8)$ & $61(47.3)$ & $2.15(1.40-3.29)$ & $2.08(1.24-3.49)^{*}$ \\
\hline & & Not affected & $94(34.2)$ & $68(52.7)$ & 1.00 & 1.00 \\
\hline & Symptom scales & & & & & \\
\hline & Systemic therapy side effects & Affected & $184(66.9)$ & $44(34.1)$ & $3.91(2.51-6.08)$ & \\
\hline & & Not affected & $91(33.1)$ & $85(65.9)$ & 1.00 & \\
\hline & Breast Symptoms & Affected & 109 (39.6) & $24(18.6)$ & $2.87(1.73-4.76)$ & \\
\hline & & Not affected & $166(60.4)$ & $105(81.4)$ & 1.00 & \\
\hline & Arm symptoms & Affected & 119 (43.3) & $28(21.7)$ & $2.75(1.70-4.46)$ & \\
\hline & & Not affected & $156(56.7)$ & $101(78.3)$ & 1.00 & \\
\hline
\end{tabular}




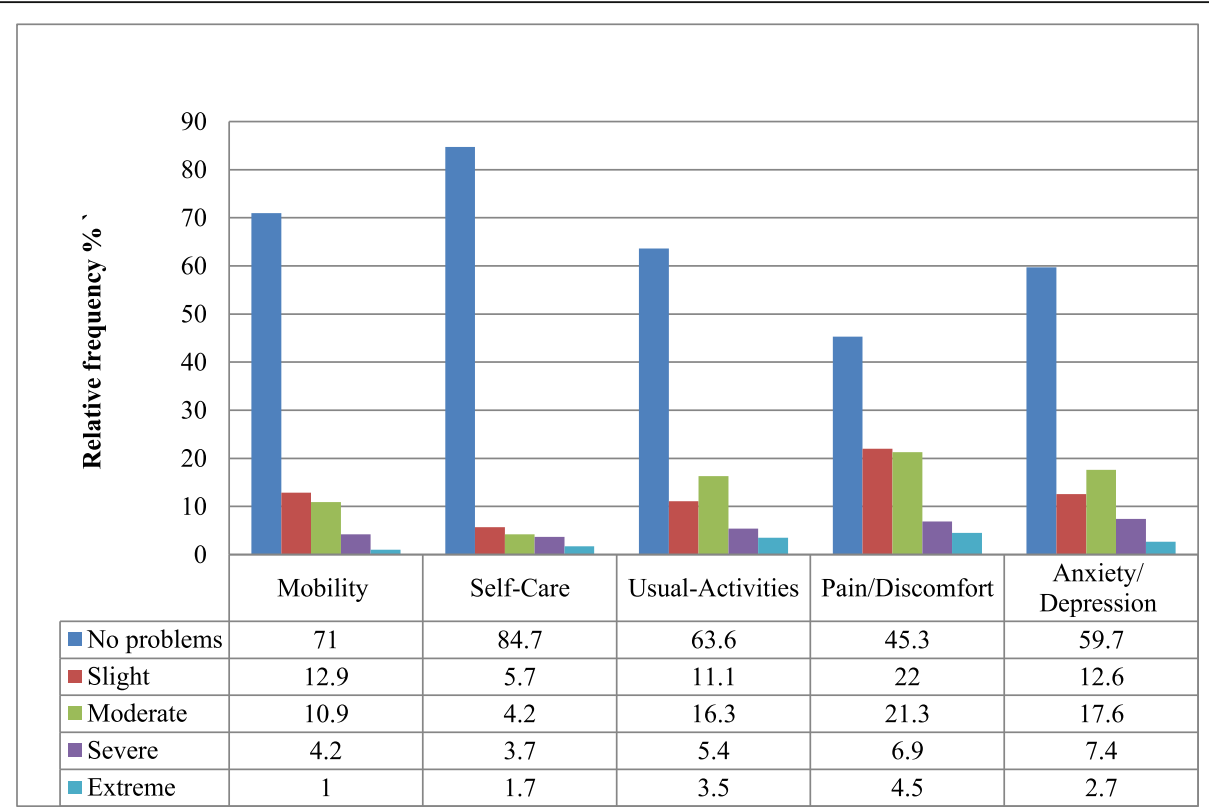

Fig. 1 Frequency distribution of the five-dimensional EQ-5D-5 L questionnaire of patients with Breast cancer at TASH, Addis Ababa, Ethiopia, 2018

potentially curable tumors to progress to incurable stages [6].

The present study indicated that cognitive functioning was one of the GQoL predictors and showed significant mean difference between cognitive functioning and treatment, which mirrors a study conducted in Tunisia [36]. Cognitive functioning of patients could be compromised due to chemotherapy, pain and disease burden of patients [37]. Patients at TASH could benefit from a follow up of investigation of cognitive functioning.

Patients whose physical condition or medical treatment caused them financial difficulties were a GQoL predictor. A study conducted in Kuwait also showed the importance of financial difficulties [30]. Future perspective was found to be another predictor of the GQoL. This finding was in contrary with the study done in Kuwait, where about two-thirds of the patients were optimistic about their future health [30]. This difference of future perspective could attribute to the lower awareness, improper understanding of the disease, associated stigma and sense of hopelessness of Ethiopian cancer patients [27].

The health state determined using EQ-VAS was found to be higher than a study conducted in Germany and lower than a study conducted in Zimbabwe [19, 38]. And the utility mean score value of the patients with breast cancer was estimated to be 0.8 , which is almost similar with Finnish populations (0.89) [39]. Thus, the utility values have been used to make health economic evaluations and decisions relevant for better health outcome of patients [40]. The current research can be used to inform patient care and future economic evaluation for breast cancer patients.

Therefore, the present study will fill the knowledge gap about the impact of socio-demographic and clinical factors on HRQoL among patients with breast cancer in the study setting. The study used a large sample size and validated measurement tools to assess the HRQoL. Furthermore, it will help healthcare providers to recognize the causes that affect HRQoL and identify the aspects of patient treatment protocol that needs to be enhanced to improve their HRQoL since its assessment is used to measure the outcome of medical intervention. It will mainly help for economic evaluation of existing and new chemotherapy drugs for patients with breast cancer.

Despite all its strengths, the study has certain limitations. Since the study was a cross-sectional study, it might limit assessment of prognosis of the patients. In addition, the study was conducted in a single setting, which might be difficult to make a generalization for the country.

\section{Conclusion}

The GQoL of breast cancer patients was below the population reference but comparable to other studies. The utility mean score was estimated to be above average $(u=0.8)$. HRQoL could be used to continuously monitor outcomes and focus should be given to pain management, and strengthening the insurance agency to improve access and affordability. 


\section{Additional files}

Additional file 1. Validated Amharic version of three data collection instruments.

Additional file 2. Table S1. Mean differences of EORTC QLQ-C30 functional scale with Socio-demographic/socio-economic characteristics of patients with Breast cancer at TASH, Addis Ababa, Ethiopia, 2018. Table S2. Mean differences of EORTC QLQ-C30 functional scale with clinical characteristics of patients with Breast cancer at TASH, Addis Ababa, Ethiopia, 2018. Table S3. Mean differences of EORTC QLQ-C30 symptom scale with socio-demographic/socio-economic characteristics of patients with breast cancer at TASH, Addis Ababa, Ethiopia, 2018. Table S4. Mean differences of EORTC QLQ-C30 symptom scale with clinical characteristics of patients with breast cancer at TASH, Addis Ababa, Ethiopia, 2018. Table S5. Mean differences of EORTC QLQ-BR23 functional scale with socio-demographic/socio-economic characteristics of patients with breast cancer at TASH, Addis Ababa, Ethiopia, 2018. Table S6. Mean differences in EORTC QLQ-BR23 functional scale with clinical characteristics of patients with breast cancer at TASH, Addis Ababa, Ethiopia, 2018. Table S7. Mean differences in EORTC QLQ-BR23 symptom scale with clinical characteristics of patients with breast cancer at TASH, Addis Ababa, Ethiopia, 2018. Table S8. Mean differences of EORTC QLQ-BR23 symptom scale with socio-demographic characteristics/socio-economic of patients with breast cancer at TASH, Addis Ababa, Ethiopia, 2018.

\section{Abbreviations}

AMHI: Average Monthly Household Income; EORTC QLQ-BR23: European Organization for Research and Treatment of Cancer-Breast Module; EORTC QLQ-C30: European Organization for Research and Treatment of Cancer; EQ5D-5 L: Euro Quality of Life Group's 5-Domain Questionnaires 5 Levels; EQVAS: Euro Quality of Life Group's Visual Analog Scale; ETB: Ethiopian Birr; GQoL: Global Quality of Life; HRQoL: Health-related Quality of Life; TASH: Tikur Anbessa Specialized Hospital; UK: United Kingdom

\section{Acknowledgments}

The authors would like to thank Addis Ababa University School of Graduate Studies for providing financial support for carrying out this study. We would like to extend our sincere gratitude to all research participants, data collectors, TASH oncology staffs as well as other institutions that supported the study.

\section{Authors' contributions}

SGS and GBG conceived the research idea and designed the study; SGS, TGF, BS and GBG performed data analysis and interpretation; SGS prepared the draft of the manuscript; SGS, TGF, BS and GBG reviewed and edited the manuscript. All authors critically evaluated the final manuscript for important intellectual content and approved the final version of the manuscript.

\section{Authors' information}

SGS is a pharmacist graduated with MSC in Pharmacoepidemiology and Social Pharmacy form School of Pharmacy, College of Health Sciences, Addis Ababa University. BS is an associate professor \& faculty lead Health Technology Assessment program at the University of Toronto, Research Chair in Economics of Infectious Diseases, Scientist \& Director at the Toronto Health Economics and Technology Assessment (THETA) collaborative and an adjust scientist at Public Health Ontario and Institute for Clinical Evaluative Sciences in Canada. TGF is a professor of Pharmacoepidemiology at the School of Pharmacy, College of Health Sciences, Addis Ababa University. GBG is an assistant professor at the school of Pharmacy, College of Health Sciences, Addis Ababa University.

\section{Funding}

Addis Ababa University funded this study for partial fulfillment of Master's degree in Pharmacoepidemiology and Social pharmacy to the first Author.

\section{Availability of data and materials}

For data protection the data set is not publicly accessible. However, data can be accessed from the primary or corresponding author upon reasonable request with a signature of data privacy form.

\section{Ethics approval and consent to participate}

The study obtained approval from the Ethics Review Board of the School of Pharmacy, Collage of Health Sciences, Addis Ababa University (ERB/SOP/40/ 10/2017) and permission was sought from the study hospital. In addition, an informed verbal consent was obtained from patients.

\section{Consent for publication}

Not applicable.

\section{Competing interests}

The authors declare that they have no competing interests.

\section{Author details}

${ }^{1}$ School of Pharmacy, College of Health Sciences, Addis Ababa University, Zambia Street, Addis Ababa, Ethiopia. ${ }^{2}$ Institute of Health Policy, Management and Evaluation, University of Toronto, Toronto, Canada. ${ }^{3}$ Toronto Health Economics and Technology Assessment (THETA) Collaborative, University Health Network, Toronto, Canada. ${ }^{4}$ Public Health Ontario, Toronto, Ontario, Canada.

Received: 22 May 2019 Accepted: 24 October 2019

Published online: 05 November 2019

\section{References}

1. Obrist M, Osei-Bonsu E, Awuah B, Watanabe-Galloway S, Merajver SD, Schmid K, Soliman AS. Factors related to incomplete treatment of breast cancer in Kumasi, Ghana. Breast. 2014;23:821-8.

2. Tao Z, Shi A, Lu C, Song T, Zhang Z, Zhao J. Breast cancer: epidemiology and etiology. Cell Biochem Biophys. 2015;72:333-8.

3. Da Costa Vieira RA, Biller G, Uemura G, Ruiz CA, Curado MP. Breast cancer screening in developing countries. Clinics. 2017;72:244-53.

4. $\mathrm{FMOH}$, Federal Ministry of Health Ethiopia 2015. National Cancer Contro Plan 2016-2020

5. Tefera B, Assefa M, Abebe B, Rauch D. Patterns of Cancer in University of Gondar Hospital: north-West Ethiopia. Journal of oncology medicine and practice. 2016;1:2.

6. Jemal A, Bray F, Center MM, Ferlay J, Ward E, Forman D. Global cancer statistics. A cancer journal for clinicians American cancer society. 2011; 61:69-90

7. Harrington S, Gilchrist L, Sander A. Breast cancer EDGE task force outcomes: clinical measures of pain. Rehabilitation oncology. 2014;32:13.

8. Perry S, Kowalski TL, Chang C-H. Quality of life assessment in women with breast cancer: benefits, acceptability and utilization. Health Qual Life Outcomes. 2007;5:24.

9. Bloom JR, Stewart SL, Oakley-Girvan I, Banks PJ, Shema S. Quality of life of younger breast cancer survivors: persistence of problems and sense of wellbeing. Psycho-Oncology. 2012:21:655-65.

10. Montazeri A, Vahdaninia M, Harirchi I, Ebrahimi M, Khaleghi F, Jarvandi S. Quality of life in patients with breast cancer before and after diagnosis: an eighteen months follow-up study. Biomedical center cancer. 2008;8:330.

11. Dang A, Likhar N, Alok U. Importance of economic evaluation in health care: an Indian perspective. Value in health regional issues. 2016;9:78-83.

12. Tikur Anbesa Specialized Hopsital (TASH). 2018. Available at: http://www.aau edu.et/chs/tikur-anbessa-specialized-hospital/background-of-tikuranbessahospital/2018.

13. Fisher, A., Laing, J. \& Stoeckel, J. 1983. Handbook for family planning operations research design, Population Council.

14. Fayers P, Aaronson NK, Bjordal K, Grønvold M, Curran D, Bottomley A. EORTC QLQ-C30 scoring manual; 2001.

15. Gusi N, Olivares P, Rajendram R. The EQ-5D health-related quality of life questionnaire. Handbook of disease burdens and quality of life measures: Springer; 2010.

16. Aaronson NK, Ahmedzai S, Bergman B, Bullinger M, Cull A, Duez NJ, Filiberti A, Flechtner H, Fleishman SB, De Haes JC. The European Organization for Research and Treatment of Cancer QLQ-C30: a quality-of-life instrument for use in international clinical trials in oncology. J Natl Cancer Inst. 1993;85: 365-76.

17. Welie AG, Fenta TG, Gebretekle GB, Stolk E, Mukuria C, Krahn MD, Enquoselassie F. Valuing health-state: an EQ-5D-5L value set for Ethiopians (ongoing study); 2018. 
18. Gangane N, Khairkar P, Hurtig A-K, San Sebastián M. Quality of life determinants in breast Cancer patients in central rural India. Asian Pac J Cancer Prev. 2017;18:3325-32.

19. Wallwiener M, Simoes E, Sokolov A, Brucker S, Fasching P, Graf J. Healthrelated quality of life in metastatic and adjuvant breast cancer patients. Geburtshilfe Frauenheilkd. 2016;76:1065.

20. Huijer HA-S, Abboud S. Health-related quality of life among breast cancer patients in Lebanon. Eur J Oncol Nurs. 2012;16:491-7.

21. Abu-Helalah M, Al-Hanaqta M, Alshraideh H, Abdulbaqi N, Hijazeen J. Quality of life and psychological well-being of breast cancer survivors in Jordan. Asian Pac J Cancer Prev. 2014;15:5927-36.

22. Dubashi B, Vidhubala E, Cyriac S, Sagar T. Quality of life among young women with breast cancer: study from a tertiary cancer institute in South India. Indian J Cancer. 2010;47:142.

23. Grabsch B, Clarke DM, Love A, Mckenzie DP, Snyder RD, Bloch S, Smith G, KISSANE DW. Psychological morbidity and quality of life in women with advanced breast cancer: a cross-sectional survey. Palliative \& supportive care. 2006:4:47-56.

24. Hopwood P, Haviland J, Mills J, Sumo G, Bliss JM. The impact of age and clinical factors on quality of life in early breast cancer: an analysis of 2208 women recruited to the UK START trial (standardisation of breast radiotherapy trial). Breast. 2007;16:241-51.

25. Jassim GA, Whitford DL. Quality of life of Bahraini women with breast cancer: a cross sectional study. Biomedical center cancer. 2013;13:212.

26. Lôbo SA, Fernandes AFC, Almeida PCD, Carvalho CMDL, Sawada NO. Quality of life in women with breast cancer undergoing chemotherapy. Acta Paulista de Enfermagem. 2014;27:554-9.

27. Woldeamanuel YW, Girma B, Teklu AM. Cancer in Ethiopia. Lancet Oncology. 2013;14:289-90.

28. Scott NW, Fayers P, Aaronson NK, Bottomley A, de Graeff A, Groenvold M, Gundy C, Koller M, Petersen MA, Sprangers MA. EORTC QLQ-C30 reference values manual; 2008.

29. Manandhar S, Shrestha DS, Taechaboonsermsk P, Siri S, Suparp J. Quality of life among breast cancer patients undergoing treatment in national cancer centers in Nepal. Asian Pac J Cancer Prev. 2014;15:9753-7.

30. Alawadi SA, Ohaeri JU. Health-related quality of life of Kuwaiti women with breast cancer: a comparative study using the EORTC quality of life questionnaire. Biomedical center cancer. 2009;9:222.

31. Fatiregun OA, Olagunju AT, Erinfolami AR, Arogunmati OA, Fatiregun OA, Adeyemi JD. Relationship between anxiety disorders and domains of health related quality of life among Nigerians with breast cancer. Breast. 2017;31: 150-6.

32. FDRE 2017. Ethiopia's Progress towards eradicating poverty an interim report on 2015/16 poverty analysis study.

33. Rahou B, Rhazi K, Hanchi Z, Ouasmani F, Benazzouz B, Ahid S, Mesfioui A. Quality of life among Moroccan women undergoing treatment of breast Cancer. British Journal of Medicine and Medical Research. 2017;21:1-11.

34. Anshabo AT, Migbaru S, Awoke D, Tigeneh W, Engidawork E. Validation of the Amharic version of the brief pain inventory for utility in Ethiopian Cancer patients. Pain Practice. 2017;17:1023-31.

35. So WK, Marsh G, Ling WM, Leung FY, Lo JC, Yeung M, Li GK. The symptom cluster of fatique, pain, anxiety, and depression and the effect on the quality of life of women receiving treatment for breast cancer: a multicenter study. Oncol Nurs Forum. 2009.

36. Masmoudi A, Frikha M, Daoud J. Feasibility of quality of life assessment in routine clinical oncology practice: a Tunisian study; 2009.

37. Pendergrass JC, Targum SD, Harrison JE. Cognitive impairment associated with cancer: a brief review. Innovations in Clinical Neuroscience. 2018;15:36.

38. Jelsma J, Hansen K, De Weerdt W, De Cock P, Kind P. How do Zimbabweans value health states? Popul Health Metrics. 2003;1:11.

39. Roine E, Blomqvist C, Kellokumpu-Lehtinen PL, Sintonen H, Saarto T. Healthrelated quality of life in breast Cancer patients after adjuvant treatments. Breast J. 2016;22:473-5.

40. Praditsitthikorn N, Teerawattananon Y, Tantivess S, Limwattananon S, Riewpaiboon A, Chichareon S, leumwananonthachai N, Tangcharoensathien $\checkmark$. Economic evaluation of policy options for prevention and control of cervical cancer in Thailand. Pharmacoeconomics. 2011;29:781-806.

\section{Publisher's Note}

Springer Nature remains neutral with regard to jurisdictional claims in published maps and institutional affiliations.

\section{Ready to submit your research? Choose BMC and benefit from:}

- fast, convenient online submission

- thorough peer review by experienced researchers in your field

- rapid publication on acceptance

- support for research data, including large and complex data types

- gold Open Access which fosters wider collaboration and increased citations

- maximum visibility for your research: over $100 \mathrm{M}$ website views per year

At BMC, research is always in progress.

Learn more biomedcentral.com/submissions 